home with a blood-pressure cuff and texted daily, the majority sent readings during the critical first postpartum week.

Similarly, an orthopedics practice manager, believing access to care could be improved, advertised same-day scheduling on the practice's website, providing his personal cell-phone number so that he became a one-person fake call center. In 3 days, he validated that such a system was both operationally and financially viable and also learned that when people seek same-day scheduling (which is hard to provide), they find scheduling within a few days acceptable (which is easier).

These two projects also illustrate a technique called minipilots: experiments integrated with operations, which may not support the small $P$ values necessary for scholarly publication but which also don't take months or

An audio interview available at NEJM.org years to conduct. A typical clinical trial

fixes the intervention at the start, follows it through its course, and isn't translated into new knowledge until the unblinding at the end. ${ }^{4}$ In contrast, successful new innovators ask, "What must be true for this idea to succeed?" and rapidly test critical assumptions in context.

Only days were required to learn that patients would text back their blood-pressure readings or would seek same-day scheduling and could be accommodated. That information didn't prove the programs would work, but it permitted early decisions about whether to keep moving forward, abandon the idea, or pivot the approach because of new insights or identified barriers. In less than 2 months, we ran half a dozen postpartumhypertension mini-pilots sequentially, each addressing a question the previous pilot had raised.

Aiming to get sedentary people walking, we launched a walking contest using smartphone pedometers and a fake back end for data collection. A mini-pilot revealed that our design inadvertently motivated active people to walk even more - but demotivated the target population, who felt defeated when they lagged on leaderboards. But observation of potent social dynamics permitted identification of new kinds of social comparisons that could get people moving. A few days of testing yielded compelling insights that justified investing in larger, more definitive trials.

With these techniques, we can test ideas faster and at lower cost to determine which ones work. Some organizations have already improved health care by using these methods to identify the intersection of human needs, business viability, and technical feasibility. ${ }^{5}$ Collectively, rapid validation techniques make us optimistic about the enduring contribution of health care innovation. They support a culture of experimentation, in which front-line clinicians and employees can turn insights into initial data, with snippets of time and small budgets. Other industries have advanced these techniques, but health care can adapt them to do much more than just build the next app.

Disclosure forms provided by the authors are available with the full text of this article at NEJM.org.

From the Center for Health Care Innovation, University of Pennsylvania (D.A.A., R.R.), and the Center for Health Equity Research and Promotion, Philadelphia Veterans Affairs Medical Center (D.A.A.) - both in Philadelphia.

1. Savoia A. Pretotype it. August 2011 (http:// pretotyping.blogspot.com/p/pretotype-it-book .html).

2. Reis E. The lean startup. New York: Crown, 2011.

3. Lessons learned from Bill Gross' 35 IPOs/ exits and 40 failures: first round review (http:// firstround.com/review/Lessons-Learned -from-Bill-Gross-35-IPOs-and-40-Failures). 4. Volpp KG, Troxel AB, Terweisch C, Mehta $S$, Asch DA. Making the RCT more useful for innovation with evidence-based evolutionary testing. Healthcare 2013;1:4-7.

5. Brown T. What happens with a design thinking approach to healthcare? Presented at TedMed 2009, San Diego, CA, February 3-7, 2009 (http://www.tedmed.com/talks/ show?id=7134).

DOI: 10.1056/NEJMp1506311

Copyright (๑) 2015 Massachusetts Medical Society.

\title{
Differential Taxes for Differential Risks - Toward Reduced Harm from Nicotine-Yielding Products
}

Frank J. Chaloupka, Ph.D., David Sweanor, J.D., and Kenneth E. Warner, Ph.D.

\author{
Tn a January 2014 report that \\ marked the 50th anniversary \\ of the first Surgeon General's \\ Report on Smoking and Health,
}

acting U.S. Surgeon General Boris Lushniak concluded that the enormous toll of tobaccoinduced disease and death is overwhelmingly the result of combustible tobacco use, specifically cigarette smoking. He called for a rapid reduction in 


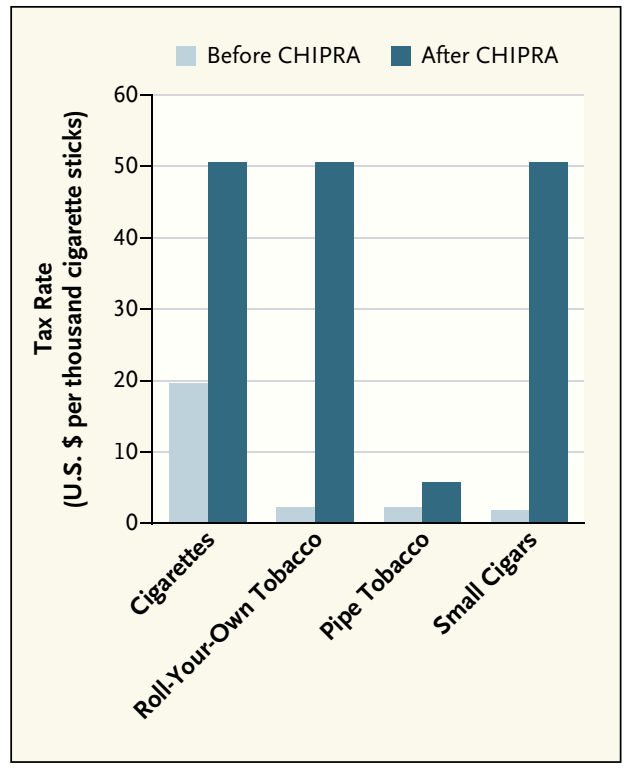

Changes in Federal Excise Tax Rates for Tobacco Products as a Result of the Children's Health Insurance Program Reauthorization Act (CHIPRA) of 2009.

Data are from the Government Accountability Office. The roll-your-own tobacco and pipe tobacco cigarettestick equivalent is based on a weight of 0.0325 ounces of tobacco per cigarette stick (i.e., per cigarette), in accordance with the Master Settlement Agreement conversion rate.

the use of combustible products to reduce the related burden of illness. ${ }^{1}$ We believe this goal could be achieved by imposing differential taxes on nicotine products - including sharply increased taxes on combustible products.

Today's nicotine consumer has a remarkable array of options, ranging from extremely low-risk products (nicotine-replacement products approved by the Food and Drug Administration [FDA]) to extraordinarily risky ones (cigarettes, which kill half of long-term users). Elsewhere on the spectrum are other lower-risk products, including low-nitrosamine smokeless tobacco products and electronic nicotine-delivery systems (ENDS, which include e-cigarettes), and higher-risk products, including combustible tobacco products other than cigarettes (such as cigars, cigarillos, and hookah tobacco). Although no one has precisely characterized the relative risk associated with each of these products, research suggests that low-nitrosamine smokeless tobacco products pose no more than one tenth the risk of cigarettes, whereas the risk associated with other combustible-tobacco products may approach that of cigarettes. ${ }^{1}$ Because ENDS products are so new and varied, the risk associated with them remains to be established, although early evidence suggests they are substantially less harmful than combustibles. $^{2}$

Extensive research demonstrates that higher tobacco taxes can help promote quitting among current users, deter initiation among potential users, and reduce tobacco use among continuing users. ${ }^{3}$ Studies have also shown that changes in the relative prices of tobacco products lead some tobacco users to switch to less expensive products. ${ }^{3}$ Given the belief that all tobacco products are seriously deleterious to health, conventional wisdom in the tobacco-control world has long been that all products should be taxed similarly. For example, the World Health Organization states that adopting "comparable taxes and tax increases on all tobacco products" is a best practice for tobacco taxation. ${ }^{4}$

To some extent, the 2009 U.S. federal tobacco-tax increases reflected this strategy: taxes on historically lower-taxed products were increased by much more than taxes on products that had previously been taxed at higher rates (see graph). Whereas the cigarette tax rose from $\$ 0.39$ to $\$ 1.0067$ per pack (a $158 \%$ increase), taxes on roll-your-own tobacco rose from $\$ 1.0969$ to $\$ 24.78$ per pound (a $2159 \%$ increase) and taxes on small cigars rose from $\$ 1.828$ to $\$ 50.33$ per 1000 (a 2653\% increase). The snuff tax rose by the same $158 \%$ as the cigarette tax. Many states have taken a similar approach, increasing taxes on noncigarette tobacco products by a greater amount than taxes on cigarettes in order to achieve greater parity between products.

As sales of ENDS have skyrocketed, interest in taxing them has grown as well. As of early 2015, Minnesota and North Carolina were the only states that had adopted taxes on ENDS. Minnesota taxes ENDS as tobacco products, levying the same tax of $95 \%$ of wholesale price that it applies to snuff and chewing and smoking tobacco. In contrast, North Carolina created a new, very low, ENDS-specific tax of $\$ 0.05$ per milliliter of consumable solution. Several other states, counties, and cities are considering legislation to impose a tax on ENDS.

The rapid evolution of the nicotine-product marketplace suggests that it's time to rethink the idea that similar taxes are best practice. We believe that national, state, and local policymakers should consider an approach that differentially taxes nicotine products in order to maximize incentives for tobacco users to switch from the most harmful products to the least harmful ones. Sizable public health benefits could derive from current cigarette smokers' switching to ENDS and other noncombustible products, includ- 
ing nicotine-replacement therapies (as the one type of nicotine product demonstrated to be safe, nicotine-replacement therapy should not be subject to any excise tax). ${ }^{1}$

Sweden, which has Europe's lowest tobacco-attributable mortality among men, provides a good example of how this approach can succeed. There, lower taxes on snus - a form of smokeless tobacco - contributed to many male cigarette smokers switching to snus. Women, however, did not switch to the same extent, which illustrates that price differentials alone are not always sufficient to achieve public health goals. ${ }^{5}$ lower-risk products while deterring users of lower-risk products from switching to more harmful ones. Higher prices for combustible products would have the added benefit of further reducing the likelihood that young people would take up smoking.

The current approach of imposing taxes on ENDS or raising taxes on cigarettes and other combustible products by the same amount as taxes on snus and other smokeless products has the opposite effect: it discourages tobacco users from switching to reduced-risk products, encourages dual use, and increases the likelihood that young people who initiate nicotine use will start with

\section{Policymakers should consider an approach that differentially taxes nicotine products in order to maximize incentives for tobacco users to switch from the most harmful products to the least harmful ones.}

The manner in which a differential taxation system is implemented will determine how well it works as a harm-reduction strategy. To alleviate concerns that low prices on ENDS and lower-risk tobacco products might encourage uptake among young people, taxes on such products could be set high enough to discourage initiation. At the same time, taxes on combustible products could be further increased in order to raise their prices relative to less harmful noncombustible products. Such a strategy would maximize the likelihood of current smokers switching to the most dangerous products.

A differential taxation strategy is not without potential problems. Decades ago, proposals were floated to tax cigarettes at different rates on the basis of tar and nicotine content. The United Kingdom and New York City adopted this approach, briefly levying special taxes on high-tar cigarettes. As evidence grew that cigarettes with lower tar and nicotine levels were no less dangerous, however, public health authorities realized that a differential taxation strategy was undesirable. Yet today the science supporting a difference in risk between combustible and noncombustible tobacco products is well established.

Given the FDA's regulatory authority over the manufacture, distribution, and marketing of tobacco products, a differential taxation strategy could be complemented by other policies, such as restrictions on ENDS marketing and strong product standards, to maximize public health benefit. Perhaps most important, as proposed in the FDA's recent "deeming" rule, the agency's authority over tobacco products could be extended to cover additional products including ENDS, opening up such items to new regulation. Policymakers could then make a product's eligibility for a lower tax rate dependent on the FDA's determination that it poses substantially reduced risk.

We believe that implementing differential taxes on nicotineyielding products on the basis of degree of risk could substantially expedite the move away from cigarette smoking that has occurred during the past half-century, especially now that there are nicotine-yielding products that pose dramatically less danger than combustible tobacco products. Nearly a fifth of U.S. adults are cigarette smokers, and smoking accounts for one of every five deaths in the United States. Failure to seriously entertain a differential taxation approach may contribute to the prolongation of the epidemic of disease and death caused by smoking.

Disclosure forms provided by the authors are available with the full text of this article at NEJM.org.

From the University of Illinois at Chicago, Chicago (F.J.C.); the University of Ottawa, Ottawa (D.S.); the University of Notting- 
ham, Nottingham, United Kingdom (D.S.); and the University of Michigan, Ann Arbor (K.E.W.).

1. The health consequences of smoking 50 years of progress: a report of the Surgeon General. Atlanta: Department of Health and Human Services, Centers for Disease Control and Prevention, National Center for Chronic Disease Prevention and Health Pro- motion, Office on Smoking and Health, 2014.

2. Nutt DJ, Phillips LD, Balfour D, et al. Estimating the harms of nicotine-containing products using the MCDA approach. Eur Addict Res 2014;20:218-25.

3. Effectiveness of tax and price policies for tobacco control: IARC handbook of cancer prevention. Vol. 14. Lyon, France: International Agency for Research on Cancer, 2011.
4. WHO technical manual on tobacco tax administration. Geneva: World Health Organization, 2011.

5. Ramström L, Wikmans T. Mortality attributable to tobacco among men in Sweden and other European countries: an analysis of data in a WHO report. Tob Induc Dis 2014;12:14

DOI: $10.1056 / \mathrm{NEJMP1505710}$

Copyright (C) 2015 Massachusetts Medical Society.

The New England Journal of Medicine 